\title{
Horta terapêutica e saúde bucal: desafios na utilização de plantas medicinais na promoção da saúde
}

\author{
I ${ }^{1}$ Nayara Rudeck Oliveira Sthel Cock, ${ }^{2}$ Creuza Rachel Vicente, \\ ${ }^{3}$ Fábio Hebert da Silva I
}

Resumo: A inserção de hortas terapêuticas no SUS fomenta o cuidado compartilhado e incentiva promissoras abordagens terapêuticas para saúde bucal, pois transporta para o centro as práticas populares em saúde. Isso implica reorganizar os serviços adotando como eixo a Clínica Ampliada. Estudos nessa esfera justificam-se pela necessidade de conhecer experiências desenvolvidas nos territórios. Relata-se o trabalho desenvolvido de março a agosto de 2017 numa Unidade Básica de Saúde do município de Vitória-ES. As experiências e efeitos dos processos de trabalho foram cartografados com a equipe de saúde bucal e usuários, a partir da construção de uma horta na Estratégia da Saúde da Família. Adotaram-se como eixos metodológicos: produção de diário de campo e realização de entrevistas semiestruturadas. A investigação produziu dispositivos de análise coletiva dos processos de trabalho e das práticas de formação, que expressam ainda incompatibilidades entre o perfil profissional demandado para estruturação da Clínica Ampliada e os reais processos de trabalho em Odontologia. Assim, compreender a construção da horta como dispositivo de criação de redes de cuidado implica delinear práticas ricas em interlocuçôes interdisciplinares e elaborar novas concepçôes de atuação em saúde bucal e possibilidades para a Atenção Primária.

> Palavras-chave: plantas medicinais; saúde bucal; Atenção

Recebido em: 20/07/2019 Aprovado em:03/03/2020 Primária em Saúde.

\author{
${ }^{1}$ Universidade Federal do \\ Espírito Santo. Vitória-ES, Brasil \\ (nayararudeck@gmail.com). \\ ORCID:0000-0002-5525-1603 \\ ${ }^{2}$ Medicina Social, Universidade \\ Federal do Espírito \\ Santo. Vitória-ES, Brasil \\ (vicentecrachel@gmail.com). \\ ORCID: 0000-0003-0182-7969 \\ ${ }^{3}$ Departamento de Psicologia, \\ Universidade Federal do \\ Espírito Santo. Vitória-ES, Brasil \\ (fabiohebert@gmail.com). \\ ORCID: 0000-0002-2809-6409
}

Revisado em: 15/10/2020 


\section{Introdução}

O saber/fazer científico hegemônico provém de uma "sofisticada" tradição de produção de conhecimento e de práticas estritamente ligadas a relaçóes de poder, que afirmam a objetividade biomédica altamente especializada e seu fundamento científico focado na doença, e não em um sujeito com histórias e conexôes com o mundo. Porém, esses aspectos têm sido questionados e crescem também os debates que afirmam a emergência da crise biomédica onde surge a ruptura da hegemonia do discurso biomédico, com a possibilidade de afirmação de modelos de atenção pautados na promoção de saúde e na autonomia.

Nesse universo, os interesses econômicos e as necessidades de acúmulo de capital estimulam um modelo de assistência à saúde baseado no consumo de equipamentos, procedimentos, atenção hospitalar, consultas médicas e medicamentos industrializados. Com o uso dos medicamentos e a possibilidade rápida de supressão da dor, o cuidado foi adquirindo outros significados e os atendimentos tornaram-se restritos a procedimentos técnicos, à solicitação e análise de exames e à prescrição de medicamentos. Assim, os "processos de cura" foram sendo simplificados e ao objetivar as relaçóes de cuidado nota-se o distanciamento da história de vida, das emoções, dos sentimentos e das condiçôes sociais das pessoas.

Segundo Tesser e Barros (2008), há uma redução da perspectiva terapêutica com a desvalorização da abordagem do modo de vida, valores, fatores subjetivos e sociais relacionados ao processo saúde-doença. Illich (1981) chama de iatrogenia cultural o efeito difuso e nocivo da ação biomédica que diminui a potência cultural das pessoas para lidar autonomamente com situaçóes de sofrimento, enfermidade, dor e morte. Michael Foucault, em conferência proferida no IMS/UERJ em 1974 e intitulada "O nascimento da Medicina social", descreve que doentes tendem a perder "o direito sobre o seu próprio corpo, o direito de viver, de estar doente, de se curar e morrer como quiserem", consequentemente sua autonomia (FOUCAULT, 1979, p. 96). É neste sentido que Martins (2004, p. 31) pontua a importância de:

[...] buscar formas criativas de expressão, abrindo brechas em meio aos padróes e práticas reinantes, recriando formas de vida micropoliticamente para que possamos dar um passo além, contribuindo para novas práticas e novos valores, novos modos de fazer, de agir, de afetarmo-nos, de conceber e vivenciar o que seja a saúde, a potência de vida e o próprio viver. 
Dessa forma, as frustraçóes e os limites trazidos com a biomedicina nos convocam a problematizar como podemos fomentar outras formas de relaçóes e cuidados. Pensar as plantas medicinais como elementos articuladores entre os saberes socioculturais e as práticas de cuidado é uma alternativa para conectar a partir de outras bases saberes específicos das comunidades ao saber científico. Essa conexão pode auxiliar na construção de caminhos paralelos à assistência médica curativista, oferecendo novos parâmetros conceituais ao modelo biomédico. Para delinear novos fluxos e aglutinar saberes, precisamos nos aproximar de conceitos e práticas que expressem distintas possibilidades de adoecer e produzir saúde, como por exemplo, o uso das plantas medicinais.

Seu uso resiste sendo transmitido oralmente e está presente no repertório etnográfico de praticamente todas as civilizaçóes, apresentando diferentes sentidos e peculiaridades culturais de acordo com o período e a sociedade considerada. Sabendo que a relação com as plantas medicinais nos ajudam compor outros sentidos para as práticas de saúde, este trabalho se estrutura a partir da produçáo de cuidado que surge nas relações e da criação de vínculos em torno da experimentação em uma horta comunitária em uma unidade básica de saúde (UBS) no município de Vitória, Estado do Espírito Santo (ES). Tratamos então essa experimentação como a criação de espaços para trocas e fortalecimentos coletivos e também como modo de colocar em questão a forma objetiva e a visão reducionista da biologia.

Quando nos referimos à horta terapêutica e às plantas medicinais, articulamos saberes e práticas populares em saúde. Agregá-las ao Sistema Único de Saúde (SUS) implica, além da incorporação de mais uma possibilidade terapêutica, a atualização de práticas tradicionais milenares, onde se imbricam, nos dias de hoje, o conhecimento científico e o popular e seus diferentes entendimentos sobre o adoecimento e formas de conduzi-lo, e principalmente, na noção de saúde (FIGUEREDO, 2013).

Botazzo (2003) expóe que a biomedicina e o regime capitalista constituíram as bases do sistema de crenças em que a Odontologia se desenvolveu no Brasil, marcando a história do setor no século XX em que o ensino concentrava esforços para desenvolver as habilidades manuais dos profissionais; salienta também os procedimentos cirúrgico-reparadores que culminam numa prática mutiladora e o caráter privado das práticas odontológicas.

Pode-se dizer que a inserção da equipe de saúde bucal (ESB) na Atenção Primária representa a possibilidade de romper com os modelos assistenciais em saúde bucal 
baseada no biologicismo, tecnicismo e curativismo em que a Odontologia se desenvolveu. Nessa perspectiva, definir o campo de atuação da ESB na atual Estratégia da Saúde da Família (ESF) é um dos desafios das equipes de Atenção Primária. As açôes de saúde bucal incorporadas à ESF vieram como forma de expansão dos serviços odontológicos e devem ser orientadas pelas necessidades reais da comunidade.

Sob essa ótica, busca-se contemplar a integralidade das açōes, articulando a promoção, a prevenção e a reabilitação da saúde, bem como o envolvimento da comunidade no processo de planejamento das açóes desenvolvidas, tornando-a corresponsável pela saúde de seus familiares. Ao pensar a atuação da equipe como possibilidade de construção de cidadania, é primordial compreender o contexto ambiental, social, político e econômico das comunidades, transcendendo o foco cirúrgico-restaurador-mutilador em saúde bucal (TURA; SOARES; CASARTELLI, 2014).

A clínica ampliada é a redefinição de trabalho da verticalização da assistência individual, familiar ou coletiva, e prevê a atuação para além das abordagens convencionais que protocolizam o atendimento aos usuários, restringem seus sentimentos, ignoram seus valores e saberes além de ofuscar suas expectativas (HAYACIBARA et al., 2010). Os autores consideram que o "objeto de trabalho" da assistência à saúde é uma pessoa, um grupo, uma família ou um coletivo institucional com doença ou risco de adoecer. O novo modelo de trabalho, portanto, transpóe a clínica tradicional, demanda uma atuação ampliada e abrangente que corresponda às necessidades de um corpo vivo, subjetivado e complexo (CAMPOS, 2003).

Pensar a incorporaçáo de hortas terapêuticas como elementos articuladores entre os saberes socioculturais e as práticas de cuidado é uma alternativa para afirmar modelos de atenção pautados na promoção de saúde e institucionalizar políticas que se comprometam com a análise do poder institucional e com a construção democrática das perspectivas de saúde e dos processos de trabalho.

A institucionalização das Práticas Integrativas e Complementares (PIC) avança na Rede de Atenção à Saúde (RAS), em relação ao uso de plantas medicinais e fitoterápicos, por meio da Política Nacional de Plantas Medicinais e Fitoterápicos e do Programa Nacional de Plantas Medicinais e Fitoterápicos. Entretanto, ainda carecem de diretrizes operacionais para sua efetiva consolidação. Desse modo, a reflexão sobre a implantação de hortas terapêuticas em UBS pode trazer elementos importantes relacionados às estratégias de implantação de tais açôes (COSTA, 
2015). Desse modo, sabendo que a relação com as plantas medicinais nos ajudam compor outros sentidos para as práticas de saúde, este trabalho se articulou a partir da produção de cuidado proveniente de vivências em torno da construção de uma horta terapêutica. Tratamos, então, essa experimentação como a criação de espaços para trocas e fortalecimentos coletivos e também como modo de colocar em questão a forma objetiva e a visão reducionista da biologia.

\section{Percurso metodológico}

O trabalho foi desenvolvido na UBS Gilson Santos, em Bairro da Penha no município de Vitória-ES, de março a agosto de 2017. O percurso metodológico teve início na observação em campo e no registro em diário de experiências, havendo participação em reuniôes e capacitaçôes para construção da horta no Parque Municipal Horto de Maruípe e acompanhamento da rotina dos profissionais da ESB.

Foram realizadas dez entrevistas com roteiro semiestruturado com a ESB da ESF ( $n=5)$ e usuários ( $n=5)$ moradores da localidade de abrangência da UBS que participaram das reuniôes e capacitaçôes para construção da horta. Os relatos de experiências foram gravados após concordância por meio de Termo de Consentimento Livre Esclarecido (TCLE) e transcritos para posterior análise de dados qualitativos submetidos à sistematização por protocolo de produção de conhecimento e observação científica. Os critérios de inclusão utilizados foram: profissionais que trabalham na ESB e usuários que fossem moradores da localidade de abrangência e que estivessem participando da construção da horta. Os critérios de exclusão foram: os profissionais e usuários que não aceitassem participar do estudo.

A seleção dos trechos para conduzir a análise das tensôes discursivas se constituiu durante o processo de escuta e organização de acordo com os objetivos e questôes propostas na pesquisa. Desse modo, buscou-se analisar os desafios e as dificuldades no processo de implementação e utilização de plantas medicinais e fitoterápicos, bem como investigar os conhecimentos, opiniôes e motivaçôes da ESB e dos usuários sobre as plantas medicinais e fitoterápicos como estratégia de promoção da saúde, contribuindo para reflexôes sobre o tema, aprimoramento das PIC e enfrentamento dos desafios e dificuldades.

Assim, após a leitura das transcriçôes, foram analisadas as principais temáticas e questóes presentes nas narrativas, buscando compreender a percepção da ESB e 
dos usuários sobre a construção da horta terapêutica e quais os sentidos, usos e as relações entre práticas de cuidado e o cultivo de plantas medicinais. Desse modo, selecionamos como eixos analíticos: horta como dispositivo de criação de redes; saúde e qualidade de vida; saúde, território e memória e desafios da integralidade: conhecimento e usos das plantas.

O trabalho foi aprovado pelo Comitê de Ética em Pesquisa do Centro de Ciências Humanas e Naturais da Universidade Federal do Espírito Santo. CAAE: 66992617.5.0000.5542.

\section{Resultados}

A imersão na rotina da ESB da ESF conduziu as anotaçóes no diário de campo e permitiu que se permeasse por vários espaços, entre eles: consultório de atendimento clínico, reuniôes de equipe semanais, visitas domiciliares e as reuniôes e capacitaçôes para construção da horta. As visitas domiciliares, conduzidas por agentes comunitários de saúde (ACS), permitiram conhecer os fluxos e as potências do território, contribuíram para aproximação das histórias das pessoas e foram importantes para disparar uma análise social sobre as realidades vivenciadas, pois revelaram produçóes de subjetividades e permitiram o acesso às necessidades $\mathrm{e}$ potencias do território.

As trajetórias percorridas na comunidade permitiram a aproximação da rotina dos moradores; ao caminhar, olhava-se a paisagem e os relevos sociais saltavam as barreiras visíveis, de modo a permitir quase um toque ou uma provocação nos sentidos. Toneli, Adrião e Galvão (2012, p. 226) expõem que:

[...] tatear implica modos de pesquisar cujo compromisso não está em representar uma
realidade suposta, mas em se deixar atravessar por processos de invenção, deixar passar a
potência de criar novas constelaçốes de possibilidade. São tremores, paixôes e exaustôes
que deslocam os órgãos de um pesquisador para fora de pretensas "neutralidades" que
delimitam mundos imóveis e estáveis.

Assim, entendemos que quando se coloca disposto a vivenciar o território suas realidades se revelam, seus contextos se aproximam e é impossível se colocar circunscrito em uma barreira de neutralidade. Em Bairro da Penha, as pessoas vivem entre escadas, quintais, becos, fogos e conflitos territoriais. A pesquisa documental revelou os números e iniquidades e a experimentação os fluxos e vivências de quem compóe o território, como neste fragmento registrado da fala de um morador: 
Na quebrada é assim, um monte de gente amontoada. Sua janela dá pra outra. Sua porta é os fundos de outra casa. Parede com parede. Janela com janela. Aqui a gente vive junto mesmo sem querer.

E neste registro do diário de campo:

Hoje parece ser um dia atípico, a unidade está vazia. Não atendemos quase ninguém. Os fogos começaram logo depois do almoço. Agora já sei o que eles significam: tem polícia subindo o morro.

Pela ótica sociopolítica, território é um espaço que sujeitos se apropriam e aglutinam força. Nele se produzem relaçóes sociais, e estas dão movimento ao espaço, assumindo um caráter político, econômico e cultural. Desse modo, trabalhar com atores sociais numa perspectiva emancipatória é fomentar o desenvolvimento de ações sob a ótica dialógica e participativa, a fim de contribuir para a construção de cenários nos quais os movimentos e saberes populares possam se fazer presentes e criar estratégias de reorientação das políticas de saúde.

Raffestin (1993, p. 150) aponta que "toda prática espacial, mesmo embrionária, induzida por um sistema de açóes ou de comportamentos, se traduz por uma 'produção territorial' que faz intervir tessitura, nó e rede". Em Bairro da Penha, surge como produção territorial da comunidade o interesse de implantação de uma horta terapêutica. Foram então articuladas reuniōes semanais com usuários, trabalhadores e gestores para viabilizar sua implantação.

Os encontros para construção da horta transformaram os participantes, pois permitiram trocas de saberes. Muito se falou sobre suas histórias e experiências, e essas reflexóes tornaram vivas no território as práticas que envolvem o cultivo de plantas medicinais. Foram discutidas informaçôes técnicas sobre cuidados com cultivo, preparo do solo, doenças das plantas, preparo de alimentos e importância dos vegetais para a saúde.

\section{Horta como dispositivo de criação de redes}

O processo de implementação da horta da saúde na UBS Gilson Santos certamente ultrapassa os limites dos encontros e oficinas de formação. As pessoas, os conhecimentos, as histórias, os conceitos de cura e as plantas não só circularam por entre esses espaços, mas também se redefiniram a partir dele e impulsionaram novos padrôes e hábitos em todos os envolvidos. 
Os conteúdos gerados a partir desses encontros foram capazes de se transformar em disparadores de novas açóes, como mudanças nas atividades cotidianas dos grupos e indivíduos e nos seus modos de pensar e utilizar plantas medicinais. $\mathrm{Na}$ visão Latour (2012), uma rede é como um modelo de organização da paisagem social, onde todos os participantes operam como atores, que fazem algo e levam outros a fazerem. Assim, não é um objeto e sim o efeito dessa descrição, o conjunto de traços deixados por esses atores em movimento.

Pode-se afirmar o potencial de criação de redes ao observar trechos de algumas entrevistas. A pesquisadora pergunta a participante “C.”: a senhora está participando do projeto da horta? O que acha do projeto aqui no horto?

Sim, e acho ótima. Uma horta educativa. Quem não tem experiência vai aprender muita
coisa. E quem já tem vai ser um ótimo lazer, ficar ali convivendo cuidando das plantas.
Tendo novas ideias[...] até mesmo aprender pra fazer em casa. Quem tem um espaçozinho
que pega sol vai aprender ter umas plantinhas. Saber como usar as verduras e também as
plantas medicinais pra fazer chá, xarope [...] é uma possibilidade de convivência que as
pessoas vão ter entre elas, né? Numa comunidade é muito bom. Tomara que as pessoas
participem e aprendam a fazer nas suas casas. Outro dia mesmo eu vi na televisão um
condomínio, não é em Vitória não, que o síndico começou a fazer uns plantios nas áreas
que batiam sol. Tudo penduradinho os vasinhos! Ai o pessoal de outro condomínio foi lá,
viram e gostaram. É menina não é que a ideia tá espalhando.

E pergunta à participante “A.", de 59 anos: de onde partiu o interesse em plantas medicinais e qual sua opinião sobre a horta?

[...] estou achando ótimo, meu interesse é de aprender fazer o cultivo. Fazer na minha casa. A importância desse projeto, que no horto vai ser pequeno, é que a gente vai se capacitar pra passar pra outras pessoas. Já aprendi que posso usar uma garrafa de pet ou uma vasilinha de plástico que quebrou ao invés de jogar fora posso plantar alguma coisinha ali, entendeu?

Ao ler esses trechos, percebe-se que a criação desses espaços fortalece a produção contínua de novos saberes e permite reafirmar a importância de trabalhar em rede. Construir possibilidades para além dos limites de territórios de saberes e práticas estanques é uma exigência ético-política para a produção de mais e melhor saúde. Para se produzir mais e melhor saúde, é necessário, então, produzir novos sujeitos e novas práticas. A rede transversal, que se produz pelos entrelaçamentos que ocorrem entre diferentes atores, serviços, movimentos, políticas num dado território - ou seja, a rede heterogênea - é que parece ser o lugar da novidade na saúde. É ela que pode produzir diferenças nas distribuiçôes de poderes e saberes (BRASIL, 2009). 
De um modo geral, houve na fala dos profissionais da saúde e dos usuários a demonstração de um alto interesse nas açôes que visem à promoção de saúde e que se aproximam das ideias de integralidade e autocuidado. Assim, a criação e manutenção de espaços como a Horta da Saúde reafirmam a promoção de saúde e permitem criar novos caminhos para as práticas de cuidado. Esses espaços atuam como dispositivos para questionar a rigidez técnico-política da biomedicina curativa e disciplinadora ainda presente no SUS e trazem possibilidades de ampliação das práticas populares de usos de plantas medicinais.

\section{Saúde, território e memória}

Os territórios, na prática, são delimitados muito mais em decorrência de fatores geográficos político-administrativos e técnico-organizacionais, mas no âmbito deste trabalho, nos aproximaremos do conceito de espaço geográfico como instância social. Assim, destaca-se que é no nível local que se manifestam as forças próprias de direito, poder e conhecimento da comunidade, já que são espaços preenchidos por sistemas de objetos e ações que se relacionam pela movimentação dos sujeitos sociais. Como pontua Pedrosa (2014, p. 765): "espaço vivo de possibilidades, o território é ao mesmo tempo local de produção e expressão dos desejos, das vontades, dos agenciamentos e da produção de subjetividades".

Surgiram dessa investigação, além de narrativas que demonstram como as pessoas se relacionam com o território, questôes sobre a relação do território com a utilização de plantas medicinais. Tal fato pode ser observado na fala das usuárias "A.", "C." e "D." quando surge a questão: por que você acha que com o passar do tempo as pessoas deixaram de usar as plantas medicinais?

$\mathrm{Na}$ medida que foram se estreitando os quintais foi tendo a necessidade de construir mais casas e cada vez ter menos área e com a facilidade de você ir na farmácia e comprar o remédio e não ter que estar trabalhando na terra trocou-se as plantas medicinais pelo medicamento de farmácia. O medicamento de farmácia é importante, mas diferente da planta medicinal ele causa outros problemas para sua saúde. A planta medicinal era o que as pessoas da roça tinham. Elas não tinham acesso a uma medicina formal. $\mathrm{E}$ isso na roça foi passando de geração em geração. A medida que foi tendo migraçáo do povo da roça pra cidade essa coisa foi se perdendo. A partir do momento que você não tem mais terra na cidade, você não vê mais terra é tudo usado pra moradia. O pedacinho que tem é a calçada. Você não tem terra nos quintais. Começou a ter os apartamentos também, aí que você não tem mesmo espaço. [...] E outra coisa, a gente é muito acomodado. É melhor você ir no médico e na farmácia e comprar uma coisa pronta que é mais rápido do que cultivar. E outra, as pessoas não tem tempo pra cultivar, pra esperar nascer, criar mudas. 
Aquilo vai morrer, vai dar praga. Você tem que cuidar. E a medida em que as geraçóes foram passando foi perdendo essa coisa de pai pra filho. Por exemplo, os meus filhos provavelmente não vão saber nem um terço do que eu sei. Os netos menos ainda. Foi se perdendo essa coisa de passar a cultura de pai pra filho, como acontece na roça. Então por isso que eu acho importante essa questáo da horta. Porque vai resgatar isso. Outra coisa, a gente tá aprendendo que você não precisa de um hectare de terra pra plantar. Um potinho, qualquer uma coisinha e você pode pendurar na parede da sua varanda, na cozinha você pode colocar em cima da pia unsvasinhos, você consegue ter uma coisa menor uma cebolinha, um alecrim. Não vou dizer que você vai ter alface e quiabo né? (Usuária A.)

É que agora virou mania tudo ir pro médico. Tudo é remédio de farmácia. E um pouco também é a dificuldade de achar as plantas. As pessoas não têm tempo na correria do dia a dia. (Usuária C.).

Ah, é porque na roça tudo era tudo mais fácil. Eu me lembro que lá, quando as pessoas ficavam gripadas. Juntavam folhas de uma porção de coisas e faziam um xarope. Era flor de laranjeira, eucalipto, guaco, muitas coisas.... Era assim, coloca um pouquinho de uma coisa um pouquinho de outra e fazia o xarope. Pronto, curava gripe assim. (Usuária D.)

Os relatos apontam para um surgimento das práticas populares de saúde no espaço rural. Mais tarde, essas práticas se adentram aos espaços urbanos e adquirem novos sentidos. Como afirma Araújo (2017, p. 22): “Os campesinos, ao migrarem para a cidade, levaram consigo símbolos, conhecimentos e artefatos que pudessem garantir sua sobrevivência e existência no espaço urbano".

Santos (1999) aponta ainda que, com a globalização, a especialização agrícola baseada na ciência e na técnica inclui o campo modernizado em uma lógica competitiva que acelera a entrada da racionalidade em todos os aspectos da atividade produtiva, desde a reorganização do território até mesmo as relações interpessoais. No espaço urbano, as relaçóes geralmente se articulam com outro referencial de tempo. Um tempo imposto e direcionado pela produtividade. Santos (1999, p. 122) nos diz:

A cidade moderna nos move como se fôssemos máquinas, e os nossos menores gestos são comandados por um relógio onipresente. Nossos minutos são os minutos do outro e a articulação dos movimentos e gestos é um dado banal da vida coletiva. Quanto mais artificial é o meio, maior a exigência dessa racionalidade instrumental que, por sua vez, exige mais artificialidade e racionalidade.

Entende-se, assim, que as relaçôes conformam instâncias de tempo cada vez mais rápidas e superficiais e que esse tempo (por exigências sociais impostas pelo sistema capitalista vigente) também se estende sobre as relaçôes de cuidado. É importante lançar o olhar ao uso de medicamentos como um fenômeno social, que se articula com os campos da economia e da política. Como Renovato (2008, p. 65) salienta: 
"O medicamento não é apenas um recurso terapêutico, pautado no modelo tecnobiomédico, mas também um fenômeno vinculado e subordinado às necessidades de produção e reprodução da força de trabalho, assumindo a forma de mercadoria”.

Isso é reafirmado na fala da cirurgiā-dentista $(\mathrm{CD} 2)$, ao responder à pergunta: por que você acha que com o passar do tempo as pessoas deixaram de usar as plantas medicinais?

É tão mais fácil pegar a medicação alopata aqui no posto. O acesso é mais fácil. O tempo das pessoas também. Muito trabalho, correria. Então, eu vou no médico se estou com uma coceirinha na garganta o médico já vai passar um antibiótico, a visão é essa... passar um antibiótico... Eu não mato serviço... Eu tomo e pronto, acabou. Já o matinho vai demorar um pouquinho mais para fazer efeito. Vai fazer efeito, mas hoje todo mundo tem pressa. O mundo está correndo atrás de náo sei o quê. Uma hora vai se chegar em algum lugar... eu só não sei aonde.

Diante disso, é importante enfatizar que estamos discutindo políticas que se afirmam em práticas de cuidado voltadas às relaçóes que demandam tempo para criação de vínculos e a construção de processos de trabalho onde diversos atores possam se constituir enquanto sujeitos dos seus processos terapêuticos. As experimentaçôes para construção da horta comunitária em Bairro da Penha criaram espaços para trocas e fortalecimentos coletivos e atuaram como dispositivos para acionar uma memória coletiva do território e das pessoas que o compóe. Como relata a usuária "D.":

Olha, se todos nós tirássemos um tempo pra ficar lembrando, meditando. Porque vai ficando no esquecimento. Por isso que é ótimo esse trabalho de agora. Pra reativar a lembrança das pessoas da utilidade que tem as plantas.

\section{Saúde e qualidade de vida}

Um traço comum encontrado nas entrevistas é que, para além do interesse sobre plantas medicinais e suas possibilidades de utilização, pode-se identificar sempre um discurso que englobava o uso de plantas numa maneira de se relacionar com nossos corpos, com saúde e doença, com o ambiente e a vida. Dessa maneira, o uso de plantas medicinais parecia apontar, algumas vezes, para uma busca por uma vida mais potente e saudável. Ao perguntar a usuária "B.", de 71 anos: a senhora usa plantas medicinais no dia a dia? Gosta?

De vez em quando eu tomo meus chás de cidreira. Tenho também o alecrim em casa que dizem que é bom pra fazer um chazinho que é calmante. Mas eu ultimamente quase não tenho usado chá de planta nenhuma. Nem remédio de farmácia. Graças a Deus estou 
muito bem de saúde. Apesar da minha idade.... Tenho 71 anos, então menina já viu né tenho que me ligar em tudo que melhora a vida.

Nos espaços para construção da horta, os assuntos entre os participantes da atividade iam além das plantas medicinais e dos fitoterápicos e permeavam conduta, receitas de alimentação, indicaçôes de cuidado no sentido da integralidade. Nota-se que há um interesse para além do universo das plantas medicinais, um interesse na manutenção da qualidade de vida, como potência. Em vários trechos das entrevistas, as falas dos profissionais e usuários se confluem nesse sentido, como por exemplo, pode-se observar ao perguntar a usuária “A.” por que estava participando da construção da horta:

Em torno de quatro anos eu descobri que tenho sério problema na lombar que limitou muito os meus movimentos. E isso me deprimiu. Procurei várias coisas. Queria alguma coisa que além de melhorar a dor devolvesse a minha alegria. Eu estava vivendo em funçáo daquilo. Pensando que ia sentir dor pro resto da vida. Então eu fui pra yoga aqui no horto. E quando lá falaram da horta me deu uma outra energia. Aquilo que eu estava procurando no interior que estava faltando poderia vir com a horta. Porque na horta você trabalhando se distrai, adquire novos conhecimentos, conhece outras pessoas.

É importante lembrar que no âmbito de nossa discussão, as práticas de cuidado direcionadas à promoção de saúde se voltam à autonomia e enfatizam a busca pela qualidade de vida. Ao perguntar quais fatores dificultam a implantação do uso de plantas medicinais e fitoterápicos na atenção primária, do ponto de vista institucional, temos a seguinte resposta da auxiliar de consultório dentário (ACD):

Tanto o governo quanto as intuiçóes financeiras e as indústrias farmacêuticas tentam retirar o máximo o autocuidado. Se você observar as pessoas de hoje em dia tem muito menos autocuidado do que as nossas avós que não sabiam nem ler e escrever direito. Quando eu falo em autocuidado estou falando em primeiro saber o que você sente. Saber diferenciar uma tristeza de uma depressão. A gente precisa identificar nossas emoções, as dores que estamos sentindo. O autocuidado é menosprezado hoje em dia porque quanto menos você souber se cuidar mais você vai depender da farmácia, do governo, do médico. $\mathrm{Na}$ minha opinião priorizar o autocuidado é priorizar a vida das pessoas.

Nesse universo, é preciso pontuar que qualidade de vida e criação de redes são temáticas intimamente relacionadas. Entende-se que os processos de interação entre os serviços e destes com outros movimentos e políticas sociais fazem com que as redes de atenção sejam sempre produtoras de saúde num dado território (BRASIL, 2009). Reafirma-se a importância de criação de dispositivos agregadores, e como afirma Pedrosa (2014, p. 760), de "espaços de criação de processos de libertação". 


\section{Desafios da integralidade: conhecimento e usos das plantas medicinais}

Os processos de experimentação de construção da horta dizem da produção de um território que é existencial, de uma memória coletiva, do fortalecimento da rede, da inclusáo efetiva dos usuários em seus projetos terapêuticos e da criaçáo e afirmação cotidiana de espaços de compartilhamento (experimentação coletiva). Essa experimentação coletiva demonstrou que a população faz uso de plantas medicinais e fitoterápicos e vai seguir fazendo, porque faz parte dos seus mecanismos de atenção à saúde e ao corpo, e porque oferece resultados considerados satisfatórios. O que podemos constatar nas transcriçôes, a seguir, de trechos das entrevistas realizadas:

Você conhece o macaé? Há muitos anos atrás, eu nasci e fui criada na roça, eu conheço mais um pouquinho as plantas. Mas nessa época eu morava em Vitória. E eu fui passear lá em Nova Venécia. E comecei a passar mal, altas horas da noite. Uma cólica abdominal muito forte. Eu tanto vomitava quanto evacuava. Aquilo eu fique fraquinha e tremendo. Então meu cunhado correu pegou o macaé e esfregou bem as folhas. Colocou nas brazas lá. Fez um chá bem forte e me deu pra tomar. Imediatamente eu melhorei e no outro dia eu não estava com mais nada. Cortou de vez o mal. Se não fosse o macaé, eu não teria aguentado. Então pra você ver o tamanho da importância que as plantas têm. Por isso elas devem ser usadas com cuidado porque elas têm um poder eficaz positivo muito bom, mas se tomar errado também, né, pode acontecer coisas perigosas, né? (Usuária D.).

A minha experiência que eu uso mesmo é o chá de cidreira pra gazes ao invés de usar logo um remédio. Romá para gargarejar quando a garganta está ruim começando a inflamar, mas ainda não tá com aqueles focos de infecção. $\mathrm{O}$ broto de goiaba, pra diarreia. Boldo quando você está com intestino ruim ou uma má digestão o boldo é bom. A folha de laranja ela é boa pra pressão, minha mãe usava pra pressão. Folha de carambola é boa pra ajudar a controlar a pressão arterial também. Deixa eu ver o que mais eu me lembro agora... devia ter anotado né? (Usuária C.).

Tem outra coisa também, algumas verduras que são boas também. Eu estava com muita dor no estômago. E aí minha cunhada falou pra bater uma batata inglesa inteira e um copo de água e tomar em jejum por um mês. E está melhorando muito. O sumo de couve também é bom pro estômago. O chá de hortelã é um chá calmante, a erva doce também é. O alecrim ele é bom na questão da pressão baixa. A rosa branca, a pequenininha, é excelente pra problemas ginecológicos, problemas de infecção é ótimo, sabe? Tranchagem é um ótimo anti-inflamatório. Arnica, também. $\mathrm{O}$ algodão tanto pode ser ingerido quanto você pode lavar o ferimento né, porque ele é um ótimo cicatrizante. A arnica, médicos já estáo passando em pílulas e pomadas. (Usuária B.).

Ao perguntar a opinião dos profissionais sobre a inserção das plantas medicinais e da fitoterapia como alternativa terapêutica na atenção primária, de um modo geral os profissionais entrevistados avaliaram como positivo e importante, pois segundo eles apresentam baixo custo, menores efeitos colaterais e a população já 
faz uso tradicionalmente, o que reafirma a importância do resgate cultural dessas práticas. Ao relacionar a prescrição de plantas medicinais e fitoterápicos à prática odontológica, os profissionais demonstram interesse, mas de um modo geral relatam que sentem falta de estímulo por parte da gestão. Diante da questão: você já indicou ou prescreveu alguma planta medicinal ou medicamento fitoterápico?

Sim, a melissa. Antigamente né, quando tinha na rede. Vinha o extrato de melissa para ajudar na pressão alta, pra gente intervir aqui. E aí a gente prescrevia pra pressão alta. Hoje a prescrição não é corriqueira. A gente nem tem mais na rede. (CD1).

Você acredita que fui prescrever um gel de arnica pra uma paciente com trismo e fui surpreendida com a informação de que só a enfermeira poderia prescrever? (CD2).

Notam-se a descontinuidade na oferta de alguns medicamentos fitoterápicos e de formas farmacêuticas fitoterápicas já oferecidas anos atrás (como as tinturas), bem como um certo descompasso em relação às informaçôes sobre os medicamentos fitoterápicos que estão disponíveis na Atenção Primária e que podem ser prescritos pelo dentista. Diante disso, fica nítido que apesar de a utilização de plantas medicinais ser incentivada, estimulada e defendida para ser inserida nos programas de Atenção Primária à Saúde, e de haver boa receptividade por parte dos profissionais, os aspectos estruturais da gestão dos serviços de saúde e o predomínio do saber biomédico ainda orientam a forma de organizar o trabalho com plantas medicinas e fitoterápicos na Atenção Primária. Esse aspecto pode ser notado na fala da cirurgiã-dentista, ao responder à pergunta: quais os fatores que dificultam a implantação do uso de plantas medicinais e fitoterápicos na atenção primária?

Como todo mundo, eu corro. Corrida da vida. Aqui dentro é uma correria danada. A gente tem que atender 16 pacientes por dia e você não tem tempo nem de olhar direito para cara do paciente. Pra você prescrever uma medicação dessa você tem que ter um tempo com essa pessoa; você tem que chegar perto dessa pessoa, ver quais os males que essa pessoa tem. O dentista não trata só de boca você trata no geral é da cabeça até os pés. Esse tempo nós não temos. A gestão nos coloca no atendimento do tira a dor. Extrai e tira dor. E é nessa situação que a gente se vê. Pra você passar um medicamento desse você precisa conversar com ele, tratar ele como um ser humano não como uma boca. (CD1).

Franco e Merhy (2003) afirmam que outro processo de reestruturação produtiva pode ser verificado na ESF, que em muitos casos mudam a forma de produzir, sem, no entanto, alterar o processo de trabalho centrado nas tecnologias duras. A formação da equipe, o deslocamento do trabalho para o território e o incentivo ao trabalho de vigilância à saúde dão uma ideia de que há mudança do modo de 
produzir saúde. No entanto, a micropolítica de organização do trabalho revela, especialmente na atividade clínica, é um núcleo do cuidado que continua operando um processo centrado na lógica instrumental de produção da saúde.

Além do nítido caráter interventivo/curativo que ainda é observado nas práticas de saúde, a fala da cirurgiá-dentista também retoma o que foi dito anteriormente em relação ao tempo "imperativo da vida urbana que está cada vez mais invadindo o campo modernizado, onde as consequências da globalização impóem práticas estritamente ritmadas" (SANTOS,1999, p. 122.).

O princípio da integralidade do SUS diz respeito tanto à atenção integral em todos os níveis do sistema, como também à integralidade de saberes, práticas, vivências e espaços de cuidado. Desse modo, muitos são os desafios para a integralidade já que temos experimentado uma rede de saúde com baixa capacidade resolutiva (apontada principalmente pela vasta literatura em saúde coletiva), voltada para prescrição, com intervençôes odontológicas sem garantia de continuidade no tratamento (conferindo algumas vezes um caráter mutilador à prática), e lógico, a grande demanda. Nesse aspecto, afirma-se a emergência de movimentos e saberes populares que possam se fazer presentes e criar estratégias de reorientação as políticas de saúde. Para tanto, torna-se necessário desenvolver ações de educação em saúde numa perspectiva dialógica, emancipadora, participativa, criativa e que contribua para a autonomia do usuário, no que diz respeito à sua condição de sujeito de direitos e coautor de seus itinerários terapêuticos; e autonomia dos profissionais diante da possibilidade de reinventar modos de cuidado.

\section{Conclusōes}

A construção da horta terapêutica permitiu a aproximação de questôes concretas do território, e a inclusão de saberes populares produziu outra organização dos processos de trabalho, com acesso mais qualificado, que se delineou em práticas ricas em interlocuçôes interdisciplinares e com outras possibilidades para a atenção primária. Nessa conjuntura, é preciso pontuar que do mesmo modo que ainda se percebe o caráter biomédico, centrado na prescrição e o controle médico sobre o corpo, o modo de viver e de se curar, são muitas as formas de resistência - formas de sobrevivência e de preservação da autonomia (MARTINS, 2004) que estão crescendo e se tornando visíveis. 
Constatou-se, nas entrevistas, que as pessoas da comunidade detêm conhecimento sobre plantas medicinais. Algumas já cultivam e fazem uso corriqueiro, de um modo amplo aceitam as plantas e a fitoterapia como opção terapêutica e referem-se também ao menor efeito colateral no uso de plantas medicinais.

Dentre os desafios e as dificuldades que se apresentaram no processo de implementação e utilização de plantas medicinais e fitoterápicos pela ESB, os profissionais apontam que seu uso não é contemplado nos processos de formação e salientam a importância de uma formação técnica para instituir tais práticas em sua rotina clínica, bem como a uniformidade no que diz respeito às normas técnicas prescritivas. Outro ponto que dificulta o uso de plantas medicinais e fitoterápicos é a organização do serviço, em que os processos de trabalho são voltados para os procedimentos curativos e a produtividade orienta o fazer clínico.

Salienta-se a importância de aproximação das equipes da Atenção Primária, para que, através do diálogo e da troca de saberes, possam divulgar a importância dessas práticas também para autonomia dos profissionais sobre a possibilidade de reinventar modos de cuidado mais humanizados, compartilhados e integrais.

Por fim, destaca-se a importância da reorientação do modelo de atenção à saúde, em que as práticas deverão ser centradas na escuta acolhedora, na ampliação do vínculo e da integralidade do cuidado, da construção de uma ciência que se oriente por uma visão integral e que seja capaz de criar alternativas que contribuam para a autonomia do usuário, sujeito de direitos e autor de sua trajetória de saúde. Assim, reafirma-se que a luta caminhe na direção contrária à lógica hegemônica e seja impulsionada pela transformação da realidade pautada nas demandas sociais. ${ }^{1}$

\section{Referências}

ARAÚJO, B. D. X. Raízes da cura: os saberes e as experiências dos usos de plantas medicinais pelas Meizinheiras do Cariri cearense. 2016. 164f. Dissertação (Mestrado em Desenvolvimento e Meio Ambiente) - Universidade Federal do Ceará, Fortaleza, 2016.

BOTAZZO, C. Saúde bucal e cidadania: transitando entre a teoria e a prática. In: PEREIRA, A.C. (Org.). Odontologia em Saúde Coletiva: planejando açôes e promovendo a saúde. $1^{\mathrm{a}}$ ed. Porto Alegre: Artmed, 2003. p. 17-27.

BRASIL. Ministério da Saúde. Secretaria de Atenção à Saúde. Política Nacional de Humanização da Atenção e Gestão do SUS. 44 p.: Brasília: Ministério da Saúde, 2009. 
CAMPOS, G. W. S. Saúde Paideia. São Paulo: Editora Hucitec; 2003.

COSTA, C. G. A. et al. Hortas comunitárias como atividade promotora de saúde: uma experiência em Unidades Básicas de Saúde. Ciênc. saúde coletiva. Rio de Janeiro, v. 20, n. 10, p. 3099-3110, 2015. Disponível em: <http://dx.doi.org/10.1590/1413-812320152010.00352015> Acesso em: 21 fev. 2019.

FIGUEREDO, C. A. A implementação da fitoterapia no SUS de João Pessoa-PB. Tese (doutorado) - Escola Nacional de Saúde Pública Sergio Arouca, Fiocruz, Rio de Janeiro, 2013.

FOUCAULT, M. O nascimento da Medicina Social. Microfísica do poder. Tradução Roberto Machado. Rio de Janeiro: Graal, 1979.

FRANCO, T. B.; MERHY, E.E. Por uma composição técnica do trabalho centrada nas tecnologias leves e no campo relacional. Saúde em Debate, ano XXVII, v. 27, n. 65, Rio de Janeiro, set.-dez 2003.

HAYACIBARA, M. F. et al. Experiência de clínica ampliada em odontologia na Universidade Estadual de Maringá. Rev. bras. educ. med., Rio de Janeiro, v. 36, n. 1, supl. 2, p. 178-183, mar. 2012. Disponível em: http://dx.doi.org/10.1590/S0100-55022012000300026. Acesso em: 2 fev. 2019.

ILLICH, I. A expropriação da saúde: nêmesis da medicina. 4. ed. São Paulo: Nova Fronteira, 1981. LATOUR, B. Reagregando o social. Salvador: EdUFBA, 2012.

MARTINS, A. Biopolitics: medical power and patient autonomy in a new conception of health. Interface-Comunic., Saúde, Educ., v. 8, n. 14, p. 21-32, 2004.

PEDROSA, J. I. S. A educação popular em saúde como prática emancipatória nas equipes de Saúde da família. In: SOUSA, M.F.; FRANCO, M. S.; MENDONÇA, A. V. M. (Org.). Saúde da Familia nos Municípios Brasileiros: os reflexos dos 20 anos no espelho do futuro. Campinas: Saberes, 2014, p. 755-784.

RAFFESTIN, C. Por uma geografia do poder. São Paulo: Ática, 1993.

RENOVATO, R. D. O uso de medicamentos no Brasil: uma revisão crítica. Rev.Bras. Farm., n. 89, p. 64-69, 2008.

SANTOS, M. A natureza do espaço: técnica e tempo - razão e emoção. São Paulo: Hucitec, 1999.

TESSER, C. D.; BARROS, N. F. Medicalização social e medicina alternativa e complementar: pluralização terapêutica do Sistema Único de Saúde. Rev Saúde Pública. São Paulo, v. 42, n. 5, p. 914-20,2008.

TONELI, M. J. F.; AdRIÃO, K.; GALVÃO, A. G. C. Tatear. In: FOnSECA, T. M. G; NASCIMENTO, M. L.; MARASCHIN, C. (Orgs.). Pesquisar na diferença: um abecedário. Porto Alegre: Sulina, 2012. p. 225-227. 
TURA, L. M. T; SOARES, K.; CASARTELLI, C. H. Atenção primaria em saúde. In: SOUSA, M.F.; FRANCO, M. S.; MENDONÇA, A. V. M. (Org.).Saúde da Família nos Municípios Brasileiros: os reflexos dos 20 anos no espelho do futuro. Campinas: Saberes, 2014, p. 178-205.

\section{Nota}

${ }^{1}$ N. R. O. S. Cock: participação na redação do artigo e no trabalho de campo. C. R. Vicente e F. H. da Silva: participaçáo na redação do artigo. 


\section{Abstract}

Therapeutic gardens and oral health:

challenges in the use of medicinal plants in health promotion

The insertion of therapeutic gardens in SUS fosters shared care and encourages promising therapeutic approaches to oral health, as it transports popular health practices to the center. This implies reorganizing the services using the Extended Clinic as an axis. Studies in this sphere are justified by the need to know experiences developed in the territories. The work carried out from March to August 2017 in a Basic Health Unit in VitóriaES is reported. The experiences and effects of the work processes were mapped with the oral health team and users, from the construction of a vegetable garden in the Family Health Strategy. The methodological axes were adopted: production of field diaries and conducting semi-structured interviews. The investigation produced devices for collective analysis of work processes and training practices, which also express incompatibilities between the professional profile required for structuring the Amplified Clinic and the real work processes in Dentistry. Thus, understanding the construction of the garden as a device for creating care networks implies outlining practices rich in interdisciplinary dialogue and developing new concepts of performance in oral health and possibilities for Primary Care.

> Keywords: medicinal plants; oral health, Primary Health Care. 